\title{
Municipal Energy Companies in the UK: Motivations and Barriers
}

\author{
Katy Roelich ${ }^{1,2}$ and Catherine Bale ${ }^{1,3,4}$ \\ ${ }^{1}$ Sustainability Research Institute, University of Leeds, UK \\ 2 Institute for Resilient Infrastructure, University of Leeds, UK \\ ${ }^{3}$ Energy Research Institute, University of Leeds, UK \\ ${ }^{4}$ Centre for Integrated Energy Research, University of Leeds, UK
}

\begin{abstract}
Municipal energy companies have the potential to contribute to low-carbon transition in the UK but could also deliver a wider range of benefits, such as fuel poverty reduction and economic growth. There are myriad ways that municipalities could engage in energy provision; however, local authorities face challenges related to matching their motivations to appropriate business models which are exacerbated by unsupportive policy and regulation. More effective decision support tools are required, in addition to changes in policy and regulation, to exploit the potential social and environmental benefits offered by municipal energy companies. An interdisciplinary approach is needed to take this initial work forward to explore business models that match actor motivations and a more complex definition of value.
\end{abstract}

Keywords: Municipal Energy Companies, Social Value, Business Models, Decision Support

\section{INTRODUCTION}

In order to provide secure and affordable energy services and avoid dangerous climate change, the UK needs rapid, systemic transformation of its energy systems to decarbonise generation and reduce demand ${ }^{1}$. The prevalent mode of energy-system operation in the UK is based on large utility companies selling units of energy to customers. Profits are increased by selling more units and by making marginal efficiency savings. This disincentivises both the adoption of low carbon technologies and the necessary scale of demand reduction².

Alternative modes of operation are emerging where infrastructure services are supplied by unconventional providers, motivated by goals other than profit. In this paper we focus in particular on the potential for municipalities to locally manage one part (or more) of the energy system. These 'municipal energy companies' could deliver a wider range of benefits, such as fuel poverty reduction and economic growth, as well as contributing to a low-carbon transition through acceleration of low-carbon technology roll-out and demand management. Despite their potential contribution to energy system transition, municipal energy companies face many constraints. These limit their growth in number and scale. Some of the most severe constraints originate from the economic regulatory system, which controls the UK's privatised energy system.

This paper investigates the motivations that municipalities have, and the barriers they face, in setting up municipal

1 J. W. Hall, J. J. Henriques and R. J. Nicholls (eds), A Fast Track Analysis of strategies for infrastructure provision in Great Britain: Technical report. Oxford 2012.

2 K. Roelich et al., "Towards resource-efficient and service-oriented integrated infrastructure operation," Technological Forecasting and Social Change (submitted) 2014. 
energy companies. We start by examining the characteristics of the current energy system in section 2 then describe how municipalities might engage in this system in section 4. We discuss some of the barriers which municipalities face in section 5 and present recommendations to overcome these barriers in section 6 .

\section{ENERGY INFRASTRUCTURE IN THE UK}

In the early $20^{\text {th }}$ century, energy was provided in the UK at a municipal level by a range of public and private actors, including municipalities ${ }^{3}$. Energy systems were small and localised, and evolved to serve specific users and locations ${ }^{4}$. The 1920 s saw the start of a phase of standardisation and centralisation to improve economies of scale, including development of the national grid, and the UK energy system was nationalised in the late 1940s ${ }^{5}$. Energy remained within state hands until the late 1980s when the government of the time started a process of privatisation, motivated by the belief that state operation of infrastructure was inefficient. During the 1990s, generation and supply were separated and the retail markets were liberalised to enable competition for both electricity and gas. Despite this, both generation and supply are dominated by large international energy companies, who supply over $98 \%$ of electricity in the UK ${ }^{6}$. The transmission network, which transports power from generation to sub-stations, was also privatised but is operated as a regulated monopoly by National Grid. Generators pay a charge to use the transmission network. Electricity is transported from substations through regional distribution network to end-users by distribution network operators (DNOs). Suppliers pay a charge to DNOs for the use of the distribution system.

This model has served the UK well by delivering operational efficiency, but has limited potential to address climate change and affordability ${ }^{1}$. There is increasing evidence that a move towards decentralisation of the energy system, (both in terms of technology and governance) could result in National Infrastructure performance increases ${ }^{1}$. This opens the way for municipal engagement in the energy system. This has the potential to deliver benefits not only in sustainability and affordability but also to contribute to local economic growth and self-sufficiency.

The scope of potential local authority engagement is broad; and could include generating, distributing and/ or supplying energy. The benefits derived from engaging in these different aspects of the system vary, as do the capabilities and motivations of local authorities. It can be difficult to determine how local authorities might engage, and with which part of the system to achieve their motivations, which can be a significant deterrent to participation. Furthermore, the physical and institutional structures that mediate the energy system have evolved to favour incumbent operators and present significant barriers to entry by municipalities. These barriers are discussed in section 5 but first we discuss how and why municipalities might engage in the energy system.

\section{METHODS}

We draw on research conducted under several research projects ${ }^{7}$ over the period from 2010 until present. In these projects over 30 interviews were conducted with stakeholders in a variety of roles across the energy systems in the UK, including local authorities, energy companies, central government and other public and private sector partners.

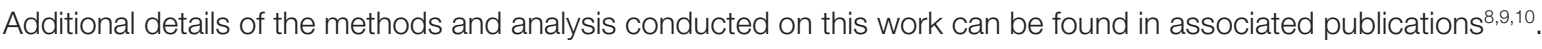
In addition, the authors have participated in informal meetings with municipal stakeholders, providing an insight into

3 R. Fouquet and P. J. G. Pearson, "A thousand years of energy use in the United Kingdom," Energy Journal, vol. 19, no. 4, pp. 1-41, 1999.

4 Hughes, Networks of power: electrification in Western society, 1880-1930. Baltimore: Johns Hopkins University Press, 1983.

5 Grid, "The National Gas Archives - Nationalisation," 2005. [Online]. Available: http://www.gasarchive.org/Nationalisation.htm. [Accessed: 08-Mar-2014].

6 Office of Fair Trading, Infrastructure Ownership and Control Stock-take. 2010.

7 See acknowledgements for details

8 C. S. E. Bale, T. J. Foxon, M. J. Hannon, and W. F. Gale, "Strategic energy planning within local authorities in the UK: A study of the city of Leeds," Energy Policy, vol. 48, pp. 242-251, 2012

9 R. Bush, C. S. E. Bale, and P. Taylor, Spatial mapping tools for district heating (DH): helping local authorities tackle fuel poverty. Leeds: Report for Chesshire Lehamnn Fund. 2014.

10 K. Roelich, "Physical and institutional challenges of infrastructure transitions: constraints and potential solutions," Phd Thesis. University of Leeds, 2014. 
the decision-making process within local authorities by using the method of overt participant observation ${ }^{11}$. This method allowed for detailed information about practices within the local authority to be drawn out and has allowed the authors to gain insight into the practical challenges of delivering municipal energy.

\section{MUNICIPAL ENERGY COMPANIES}

There are myriad ways that municipalities could engage in energy provision, depending on the scope of their engagement and on their motivations for engagement. These dimensions of engagement are discussed in this section, with examples.

\section{SCOPE OF MUNICIPAL ENERGY COMPANIES}

There is potential for municipalities to engage with each or many parts of the energy system, including generation, distribution and supply and a real appetite to take more control of local energy provision ${ }^{12}$.

\section{GENERATION}

There a nascent movement of local authority-led energy generation projects which tend to generate energy to supply local authority properties ${ }^{13,14}$. Although many local authorities have set up an Energy Services Company for the purpose of operating generation equipment, self-supply excludes the need for a separate 'supplier' and reduces governance complexity. Many of these projects use combined heat and power, which has significant potential to reduce local authority energy bills and contribute to carbon emissions reductions targets ${ }^{15}$.

\section{DISTRIBUTION}

There are few current examples where local authorities have developed network infrastructure or set up independent distribution operators. One of the exceptions is the Thameswey project initiated by Woking Borough Council, that developed a private-wire network between electricity generation and end-users as well as the examples of district heat networks in the UK ${ }^{15}$. However, there is a great deal more potential for local authorities to engage in distribution, in particular the implementation of smart grids to better balance supply and demand. This not only contributes to emissions reductions but could also offer significant benefits with regard to economic development ${ }^{16}$.

\section{SUPPLY}

Many local authorities have made initial ventures into supply by engaging with the Big Switch campaign ${ }^{17}$, teaming up with Which? magazine to negotiate bulk discount for a group of customers willing to switch suppliers ${ }^{18}$. It is possible that local authorities could buy energy in bulk from the wholesale market and sell energy directly to customers in their

11 D. L. Jorgensen, Participant Observation: A Methodology for Human Studies. London: Sage Publications, 1989.

12 Core Cities, Core Cities Growth Prospectus Policies Step 6 : Power Up the Cities. 2013.

13 J. P. Thorp, "Woking: Driving Sustainable Innovation," in Sustainable Innovation: Building \& Construction Technologies, 2007

14 D. Hawkey, "District heating in the UK: A Technological Innovation Systems analysis," Environmental Innovation and Societal Transitions, vol. 5, pp. 19-32, 2012

15 J. P. Thorp, "Delivering affordable and sustainable energy: the results of innovative approaches by Woking Borough Council, UK," in System Innovation for Sustainability 4: Case studies in sustainable consumption and production - Energy use and the built environment, vol. 44, S. Lahlou, Ed. Greenleaf Publishing Limited, 2011.

16 S. Hall and T. J. Foxon, "Values in the Smart Grid: the co-evolving political economy of smart distribution.," in ESEIA-IGS Conference: Smart and Green Transitions in Cities / Regions: 24-25 April 2014, 2014

17 Which? "More than 36,000 people make The Big Switch," 2013. [Online]. Available: http://www.which.co.uk/news/2012/06/ more-than-36000-people-make-the-big-switch-287912/.

18 Leeds City Council, "Leeds residents to use people power for cheaper energy," 2013. [Online]. Available: http://www.leeds.gov. uk/news/pages/Leeds-residents-to-use-people-power-for-cheaper-energy-.aspx. 
locality and beyond, which would require them to comply with supply codes, and to apply for, and hold a supplier licence. The Greater London Authority is the first municipality in the UK to hold a licence to supply. It will initially buy surplus electricity produced by London's boroughs and public bodies before selling it on, at cost price to other public sector bodies. If successful the scheme may extend to include private sector energy producers in London. It is hoped that bulk buying in this way could reduce prices for residents and improve the viability of local energy projects ${ }^{19}$.

\section{MOTIVATIONS AND BENEFITS OF MUNICIPAL ENERGY COMPANIES}

The motivations of municipalities seeking to enter the energy market are diverse; table 1 presents a selection of motivations for engagement in municipal energy companies reported by local authorities ${ }^{9,12}$. The motivations can be delivered by engagement with different parts of the system, as described in the examples given in the previous sections. For example, fuel poverty could be addressed by engagement in supply and controlling unit charges, reducing costs to customers. Conversely; emissions reductions motivations might be best achieved through engagement with low-carbon supply. Local authorities often report multiple motivations which can make it difficult to identify the most appropriate scope of engagement. Furthermore, motivations vary significantly between different authorities, which means that there is little standardisation and little opportunity to learn from predecessors.

Table 1: Motivations for engagement in municipal energy companies co,12 $^{9}$

\begin{tabular}{|l|l|}
\hline Area & Motivation \\
\hline Economic & Competitiveness \\
\hline & Job creation \\
\hline Social & Economic growth \\
\hline & Fuel poverty \\
\hline Environmental & Regeneration \\
\hline Other & Fairness e.g. tariff discrepancy \\
\hline
\end{tabular}

\section{BARRIERS FACED IN SETTING UP MUNICIPAL ENERGY COMPANIES}

In addition to challenges relating to marrying scope and motivations, municipal energy companies face a series of barriers during set-up and operation.

\section{INTERNAL BARRIERS}

Local authorities have not had a role in energy governance, beyond spatial planning, since the energy system was merged and nationalised in the 1940s. Furthermore, a cultural ethos of aversion to risk and revenue generation limits the willingness of local authorities to engage in infrastructure operation ${ }^{20}$. The institutional lock-in created by historic constraints on the role of local authorities limits many to traditional ways of operating and a risk-averse ethos persists ${ }^{20}$. Changes in financing and accounting practices could be slow in the face of this lock-in, limiting the number of local authorities willing to get involved8.

The development stages of projects take a great deal of resources, and in the face of reducing budgets for core activities, it is often difficult to find or justify this resource. It's not just the quantity of the resource but a lack of internal technical knowledge, which leads to a lack of confidence in decision making processes ${ }^{8}$. This is particularly important

19 Greater London Authority, "Licence Lite," Iondon.gov.uk, 2013. [Online]. Available: http://www.london.gov.uk/priorities/ environment/tackling-climate-change/energy-supply/licence-lite. [Accessed: 31-Dec-2013].

20 D. Hawkey, J. Webb, and M. Winskel, "Organisation and governance of urban energy systems: district heating and cooling in the UK," Journal of Cleaner Production, vol. 50, pp. 22-31, 2013 
when identifying the scope of engagement most likely to deliver outcomes of importance to a particular local authority, which as discussed in section 3.2, can vary significantly.

\section{EXTERNAL BARRIERS}

The post-privatisation policy and regulatory system has evolved around, and favours, the mainstream mode of operation, which is profit-oriented, throughput-based and large-scale ${ }^{21}$. The scale and motivations of municipalities differ greatly from the mainstream, which means they face a series of constraints that limit their potential to contribute to energy service delivery. Our analysis has identified a series of crucial constraints to current activities and future developments.

The pro-market focus of regulation views markets and competition as the most effective way of meeting society's choices and considers that policy should foster markets as far as possible. However, this reinforces the narrow definition of value in purely economic terms, which overlooks the non-monetary benefits that end-users receive from more efficient and inclusive infrastructure operation, such as reduction in fuel poverty (which is barely affected by price control) and local employment.

Specific regulator instruments, such as Supplier Licencing constrain small providers. Although the motivation for licencing is justifiable, the licence terms are extremely onerous for small suppliers and act as a severe deterrent constraining the size of individual operations.

\section{POTENTIAL RESPONSES TO BARRIERS}

More appropriate support is needed to help local authorities identify how to match the scope of their engagement with their motivations. This might require decision support tools that enable local authorities to integrate social and environmental value into decision making processes as well as economic value.

A more integrated approach to policy is necessary, which respects the range of values and priorities of local authorities. This includes adapting funding and incentive criteria to encourage wider benefits, such as fuel poverty reduction. Social benefit generated by more local schemes must be captured and assessed on a more equal footing with financial benefit. A new approach to accounting and valuation in required which takes into account these non-monetary benefits as well as the benefits derived by future users, for example, by avoiding dangerous climate change.

Targeted support for municipal energy companies is necessary to reduce risk and uncertainty and drive innovation. Targeted support offers advantages over market mechanisms, particularly for initiatives at an early stage of development ${ }^{22}$. Support is particularly important during crucial stages of scaling up from a small experiment to a fully commercial business.

New approaches to regulation are required that realign the goals of economic regulators with wider goals of transitioning to a low-carbon energy system. Sustainability goals need to be equal to, or take precedence over, economic goals. This should be accompanied by simplification of supply licencing arrangements, including removal of the need for smaller operators to enter into agreement with large, incumbent operators.

21 C. Mitchell, The political economy of sustainable energy. Palgrave Macmillan, 2010.

22 Gross et al., "On picking winners: The need for targeted support for renewable energy." 2012 


\section{CONCLUSIONS}

It is clear that there are a number of diverse motivations for municipal actors in delivering energy and this diversity in motivations has the potential to deliver a wider range of benefits than the incumbent energy providers. However, these motivations need to be matched to appropriate scope of engagement in energy provision. The capabilities of local authority actors and current energy policy and regulation can present significant barriers to identifying and implementing appropriate business models for municipal energy companies. More effective decision support tools are required, in addition to changes in policy and regulation, to exploit the potential social and environmental benefits offered by municipal energy companies, which are not currently captured with standard economic models.

An interdisciplinary approach is needed to take this initial work forward to explore business models that match actor motivations and a more complex definition of value.

\section{ACKNOWLEDGEMENTS}

This work was supported by a grant from the Chesshire Lehmannn Fund, the Engineering and Physical Sciences Research Council for supporting this work under grant EP/G059780/1 'Future Energy Decision-Making for Cities Can Complexity Science Rise to the Challenge?' and grant EP/J00555X/1 'Land of the MUSCos'. The authors are grateful to the funders and would also like to thank those that participated in interviews and meetings throughout. Thanks also to Professor Peter Taylor and Dr Julia Steinberger for helpful comments and advice throughout and Ruth Bush and Tina Schmieder for their significant contributions to interview work. 